\title{
The Study of Learning Support Services Status in National Quality MOOCs
}

\author{
Guang Liu \\ The Centre of Education Technology \\ South China University of Technology \\ Guangzhou Guangdong, China \\ fjygliu@scut.edu.cn
}

\begin{abstract}
Quality assurance is considered to be a common concern in online open course construction. Learning support service is a key factor to assure the quality of open online courses. This paper begins from four aspects, namely design and development of learning resource, learning activity service, learning evaluation support and platform environment, to analyze two operation platforms of online open courses named "icourse" and "xuetang online". It thus puts forward measures through building course construction principles and using technical methods to improve learning support.
\end{abstract}

Keywords-online open courses; learning support services; icourses; xuetang online; resource sharing courses

\section{INTRODUCTION}

It is common to worry about the quality of online open courses which is affected by teaching resources, learning support services and self-study ability. The quality is mainly assured by providing service support like learning content, activities evaluation and on. "icourse" and "xuetang online" are respresentative online operational platforms in China. This paper compares the difference of learning support services on both platforms, and draws a conclusion on the present situation, features of learning support services and measures to improve learning quality.

\section{PRESENT SITUATION OF LEARNING SUPPORT SERVICE IN THE RESOURCE SHARING COURSES ON "ICOURSE" PLATFORM}

With university students as service principal, resource sharing courses are complete and systemic online courses also targeting social learners [1]. "icourse" is a course sharing platform designated by Chinese Ministry of Education. It have various courses and a wide range of services [2].

\section{A. Present Situation and Choice of Research Samples of Quality Resource Sharing Courses Construction}

So far, there are 2,911 quality resource sharing courses across the country [3]. This number overtaking three major MOOC platforms in the United States in terms of the quantity and construction speed. Samples in this paper were selected from the resource sharing courses with top ten populations of learners in "icourse".

\section{B. Learning Support Services in Resource Sharing Courses}

1) Development design services of learning resources

In the aspect of modular functional design, the home page not only provides learning instructions, but also illustrated course descriptions, including metadata such as name, credits, host universities, etc., and text documents which contain course outlines, calendars and other course related information. The knowledge and skill points in each chapter were integrated in a way of hyperlinks to make it convenience for learners' selfregulated learning.

Teaching resources in resources sharing courses include teaching video, ppt, exercises and other media forms. Videos occupy the most important place on the web page. There are always full videos with varying credits from 32 to 200, each taking 50 minutes on average. The majority of them are filmed in multimedia classrooms, and few in computer rooms, drafting rooms and other places. Most videos show class teaching and some also have a few contents such as group seminars and site simulation.

\section{2) Learning activities support service}

There are no regulations on when the classes will start and finish on the resource sharing courses on the "icourse" platform. Learners can take courses whenever they like. Learning activities consist of classroom interaction, Q\&A, learning notes, teaching activity design, etc. Courses are divided into two interfaces, namely "start learning" and "participate classroom interaction". "Start learning" page mainly provides videos function and a "take note" button on the right side of the window is designed to pause the video. In contrast, "classroom interaction" page only shows questions and answers for interacting. The learning activity support function in the sample courses in this paper is not well-utilized, apparently manifested in the inadequate classroom interaction: ten courses with only averagely 1530 interaction in each course and the highest figure per person is merely 1.84 . The inadequate interaction shows the low participating level between teachers and students.

\section{3) Learning evaluation support}

Learning evaluation, a process which evaluates learning in feasible means according to learning objectives, plays an important role in the learning in the online open courses. Its prompt learning test and result feedback helps learners to do 
timely review summary and adjust learning speed. A complete evaluation system is considered to be one of the biggest features for excellent online open courses. To date, the learning evaluation function in "icourse" resource sharing courses has not completed yet, for the reason that it doesn't have online testing function. Enough attention has not been paid to evaluation part during the course construction. There are only evaluation methods and standards listed in course description without any corresponding evaluation requirement in each chapter.

\section{4) Learning environment support on the platform}

Learning environment provides both hardware and software conditions for learning behavior. Learning environment is closely connected with learners and meanwhile affect the learning feelings and result. Ministry of Education have learned lessons from the quality course construction and has built "icourse" as a unified operation platform for the China quality open courses. Those courses are similarly designed in function to create a unified self-study environment for learners. Having drawn on the lesson from the success of Web2.0, "icourse" has course interaction, Q\&A and the like parts to tailor rules for learners to recommend popular and attracted courses. There are not only study communities within the course, but also social softwares from well-known websites such as Sina, Tencent and Netease in each learning process to widen interpersonal communication.

\section{THE FEATURES OF LEARNING SUPPORT SERVICE IN “XUETANG ONLINE” COURSES}

Tsinghua university has developed "xuetang online" platform based on open source code Open edX, providing free online courses globally. This paper selects some representative courses to analyze its features of learning support services.

\section{A. Development and design services for learning resources}

Similar to "icourse", metadata information such as course description and teacher list are shown on the homepage of "xuetang online". There are promotion videos for each course, usually a-few-minute length with delicate shot, carefullydesigned content and scenario simulation to intrigue learners' interest by blending the meaning and core content of the course in beautiful scenes and exquisite shot.

The course learning page is mainly designed with modules including courseware, course information, schedule and teaching plan. The page of courseware which mostly contains video resources is divided into two screens, the left one showing tree structure of the course and the right one demonstrating videos. Learners can rapidly select videos they want to learn by corresponding hyperlinks. The length of videos is usually all around several minutes to no more than twenty minutes. Videos were designed in microstructure. Subtitles are usually placed downside the video or at its right side where learners can do video searching and quick jumping.

\section{B. Learning Activity Support Services}

"Xuetang online" creates a learning experience similar to on-campus courses with exact start time, and regular weekly updated teaching content and homework that are sent through email to remind learners. After logging in courses, learning schedule will be shown in the content. The teaching group will usually stop learning activity support when courses finish. This time setting which brings off line learning experience decreases the number of drop-out caused by learning procrastination and moreover encourages continuing learning.

Course learning interaction is achieved via discussion section and email. In the only discussion section, learners can randomly jump to different chapter section and their discussion is ordered through date, number of votes and number of comments. Therefore, they can do key words searching and voting, get to know what are the heated topics and whether they have received replies on their interested topics.

\section{Learning Evaluation Support}

"Xuetang online" provides easy, complete evaluation function with prompt feedback. Course performance is examined by daily homework and final term scores in certain proportion. The homework module after videos in each chapter helps learners to better understand their learning contents. There are two forms of objective questioning exercises: choice questions and gap filling. The scores of exercises were calculated by the accuracy of the answer. Final term examination is designed in an online examination system on the platform, applied through uploaded homework or online examination. Finally, learners who have passed the examination will be rewarded certificates by the platform, host universities or leading lecturers which depends on the rules of the platform or the university.

\section{Learning Environment Support on the Platform}

"Xuetang online" has explored a new HTML5 video player which gets rid of the edX threshold on YouTube video player for Chinese mainland students. The platform presents a simple appearance with a full-text searching technology that makes it much quicker and more convenient to search for courses. Meanwhile, the platform is improving its visual formula editor, handwriting recognition, learning behavior analysis and mobile clients development to bring better learning experience for learners in the future.

\section{MEASUREMENT TO IMPROVE LEARNING SUPPORT SERVICES IN ONLINE OPEN COURSES}

There are still defects on learning support services in online open courses in China. Forming correct operation principles and taking in overseas online open courses are required in order to improve the present situation and offer a more effective learning support service.

\section{A. Professional Team Operation Need to be introduced to Change the Original Quality Course Operation Principles in Online Open Courses}

There never fail to be unsuccessful open course cases run by prestigious universities throughout the world, the primary cause being position error on the online open course character and short of the professional intervention. Compared with common class courses, online open courses greatly lack in faculty and student resources, teaching content, media environment and so on. As a result, the online course can keep going only under the lead of host institution and universities and a professional team composed of leading lecturers, 
instructional designers, media technicians, course construct supervisor, etc. with reasonable profit contribution.

\section{B. Specific Learning Support Services is Necessary}

In the contrast of courses on "xuetang online", it can be seen that specific learning support needs to be carried out to improve online open course in sections at least as followings:

\section{1) Scientific and reasonable learning resource design}

What is special for online open courses learning is that it's mobile and fragmented. Therefore, learning content needs to be reasonably conversed into micro-resource by being divided into separate parts according to knowledge points and short time principles. It can also help to keep the course content intact and systematic through strengthening the connection in different knowledge points by creating visual sections like module sections and tree structure of courses. The teaching design during the course development is relied on psychology behavior in knowledge spreading and its regularity, target audiences' academic backgrounds, knowledge level and cognitive features. The design is also applied in the aspect of media psychology and production to complete contents like story construction, spot choice and lens language to provide visual comfort and intrigue interest for learners.

2) Arouse learning motivation and interest through various methods

One feature of online open courses is that both students and teachers walk away after getting or giving scores. Therefore, interactive methods should be taken to attach students to the course and bring them sense of identity and motivation. Functions like commenting, questioning and socializing on the platform will take full effect when students and teachers master various interactive technologies which may be a little bit complicated for some of them. Besides, leading lecturers and course instruction should give immediate reply on focused problems, especially noticeable ones to strengthen learning effect. This will also help to build an active course community in social softwares.

\section{3) Construct rational evaluation mechanism}

Learning evaluation plays an effective role in improving learning quality, even simple self conclusion and evaluation does a little help to understand and grasp learning content. It is necessary to set enough self evaluation and online examination parts based on the course character and contents, because tests are not only a way to show learning results but also a way to improve learning quality. Contents that can be tested through objective questions can rely on the automatic evaluation in the system; contents tested through subjective questions need exacting evaluation rules, evaluation group, interactive evaluation among group members and the like to be achieved.
4) Explore the technical potential to improve teaching quality

The large population of learners which has never been discovered in class courses makes it the biggest feature of MOOCs course. Distant education usually improves learning support by increasing students, however, this method cannot be used in online courses owing to inadequate learning funds and students' individual difference. Technology methods like big data digging are needed to solve this problem. For example, the analysis of the data of regular learning problems provides a scientific instruction for teachers to give specific answers and adjust teaching contents. This analysis can also be used in course recommendation and result estimation according to particular learning experiences and interest of learners and meanwhile make sure learners attend the tests on their own to improve the credibility of the tests.

\section{CONCLUSION}

The programmatic documents like "The National Outline of Reform and Development Plans in Middle and Long Term Education" regards quality resource sharing as the essential element to achieve modern education. Online open courses take the greatest responsibility for quality resource sharing in universities and improvement for higher education reform. Based on the comparison between "icourse" resource sharing course and "xuetang online" MOOC course to analyze the present situation and features in learning support service, online courses also play an effective role in helping future online course construction and operation quality improvement.

\section{ACKNOWLEDGMENT}

This research was financially supported by the project "The construction and applied strategy of high-level university online open courses" from Guangdong university technical education reform program in 2015(project number: 2015033), "Teaching method reform in MOOCs experimental courses of economy and management" (project number: 2015011), "Research on the development and application strategy Facing of E-textbooks on E-learning methods" from Twelfth FiveYear Plan of education science in Guangzhou (project number: 2013A041).

\section{REFERENCES}

[1] Tsinghua University. About Xuetang Online[Z]. 2016. http://www.xuetangx.com/partners.

[2] Icourse. 2015. http://www.icourses.cn/mooc/.

[3] Zhang WY. The Analysis on Causes of Successful and Failed Online Education in overseas Universities[J]. Chinese Distant Education. 2005(11): 33-36. 